\title{
Short Communication: \\ Leaf architectural characteristics of Cinnamomum cebuense Kosterm. (Lauraceae) distributed in different geographical locations, taxonomic identification and conservation concerns
}

\author{
EDGARDO P. LILLO ${ }^{1,2, \vartheta}$, INOCENCIO E. BUOT JR., ${ }^{3,4, v}$, ARCHIEBALD B. MALAKI ${ }^{1,2}$, \\ STEVE MICHAEL T. ALCAZAR ${ }^{1,2}$, RAAMAH ROSALES ${ }^{1,2}$, JOHN LOU B. DIAZ ${ }^{1,2}$, \\ BERNARDO R. REDOBLADO ${ }^{1,2}$, GLORY GRACE G. GEALON ${ }^{1,2}$ \\ ${ }^{1}$ Cebu Technological University. Argao Campus, Argao 6021, Cebu, Philippines \\ ${ }^{2}$ Forest Biological Sciences, College of Forestry and Natural Resources, University of the Philippines Los Baños. College Laguna 4031, Laguna, \\ Philippines. Tel: +63-932-9654073; ‘email: lillo_edgardo@yahoo.com \\ ${ }^{3}$ Institute of Biological Sciences, University of the Philippines Los Baños. College Laguna 4031, Laguna, Philippines \\ ${ }^{4}$ Faculty of Management and Development Studies, The Philippines Open University. Los Baños, College Laguna 4031, Laguna, Philippines. \\ Tel.: +63-922-8140447; ‘vemail: inocencio.buot@upou.edu.ph
}

Manuscript received: 31 August 2019. Revision accepted: 25 December 2019.

\begin{abstract}
Lillo EP, Buot IE Jr., Malaki AB, Alcazar SMT, Rosales R, Diaz JLB, Redoblado BR, Gealon GGG. 2019. Short Communication: Leaf architectural characteristics of Cinnamomum cebuense Kosterm. (Lauraceae) distributed in different geographical locations, taxonomic identification and conservation concerns. Biodiversitas 20: 246-251. Populations of Cinnamomum cebuense Kosterm (Lauraceae) distributed in three geographic locations: Tabunan in Cebu City (type locality), Nug-as in Alcoy, Cebu and Mount Nacolod in Southern Leyte, were examined in the study to clarify reports of the existence of its existence outside of Cebu Island. The primary aim of the study was to investigate the identity of three Cinnamomum cebuense populations in terms of leaf architectural characteristics of Cinnamomum cebuense Kosterm. (Lauraceae). Herbarium specimens were examined and results showed that the populations from the three localities, were more or less similar in terms of the primary and secondary vein characters. However, in terms of the tertiary vein characteristics, which usually differentiate species, only Alcoy and Tabunan (Cebu Island) populations were consistently similar. The Mount Nacolod populations were very different, implying a different taxonomic identity and necessitates further investigation. Cinnamomum cebuense is endemic to Cebu Island and has to be conserved and protected in the wild.
\end{abstract}

Keywords: Cinnamomum cebuense, leaf architecture, morphological, Mount Nacolod, Nug-as forest

\section{INTRODUCTION}

Cinnamomum cebuense Kosterm. (Lauraceae), commonly known as kaningag or kalingag, is an endangered endemic Philippine tree found only in Cebu Island, Philippines (Baroga et al. 2004). The species is distributed at low elevations in the last remaining forest fragments of the Tabunan forest, Nug-as forest of Alcoy, and Dalaguete, Cebu. There are unofficial reports that the species of $C$. cebuense in Tabunan forest was different from that in Alcoy, Cebu. Unverified reports from Department of Environment and Natural Resources Cebu said that $C$. cebuense can also be found in the neighboring islands of Camotes and Siquijor. Furthermore, Flora \& Fauna International in its unpublished report during its expedition in 2013 in Mount Nacolod, Southern Leyte, also claimed that several mother trees of $C$. cebuense exist in the site. To verify some of these claims, the species' leaves can be compared using leaf architecture. Leaf architecture is a traditional morpho-anatomical method in characterizing plant species (Global Trees Campaign 2011). The use of leaf architecture and leaf morphology, in general, has already been presented in different paleobotanical and recent systematic studies (Celadiña et al. 2012). This method has been used in part as a tool to resolve taxonomic controversies (Fuller et al. 2005; Loutfy et al. 2005). Although flower and fruit characters provide useful information, there are situations in which plant specimens available for study are sterile. Tropical botanists usually face this problem since many tropical plants flower infrequently and irregularly. In the Philippines, several scholarly works have used leaf architecture to classify species. These include the works of Banaticla and Buot (2004), worked on the genus Psychotria (Rubiaceae), Obico et al. (2007) worked on the genus Epipremnum and Rhaphidophora (Araceae), and Larano and Buot (2010) demonstrated that four families (i.e. Sterculiaceae, Malvaceae, Tiliaceae, and Bombacaceae) in the order Malvales (sensu APG) could be lumped into one family, that is Malvaceae, based on the similarity of their leaf architectural characteristics. Baroga et al. (2004) noted that leaf attachment, petiole features, laminar shape, base and apex shape, margin type and blade class were important diagnostic characters, while the secondary and tertiary vein categories and spacing and angle were the most useful characters in separating Philippine species of Terminalia $\mathrm{L}$. 
from each other. The goal of systematics is to explore important and relevant evidence that are useful in describing, classifying, and identifying taxa (Baroga et al. 2004). To this point, works done by taxonomists using leaf characters to establish similarities and dissimilarities among species are yet to showcase the full taxonomic potential of leaf architectural characters, which makes it a focus of exploration (Kpadehyea et al. 2014).

The primary aim of the study was to compare the leaf architectural characteristics of the population of $C$. cebuense distributed in different geographical locations. Additionally, the study identified some strategies to conserve C. cebuense.

\section{MATERIALS AND METHODS}

Leaf specimens collected from Nug-as of Alcoy, and Tabunan forest of Cebu City of Cebu Province, the Philippines (Figure 1) as well as Mount Nacolod, Southern Leyte Province, the Philippines (Figure 2) were used in the study. They were brought to University of the Philippines Los Banos for observation and examination, and were deposited at the IBS Botanical Herbarium (PBDH). Leaf samples were taken from the third mature leaves, the ones fully exposed to sunlight ( $\mathrm{Pi}$ et al. 2009). Ten mature leaf samples for each specimen were used in the study. The leaf samples were examined using a hand lens with higher magnification. The leaf architecture characteristics and terminologies from the Leaf Architectural Working Group Manual (LAWG 1999) was used to describe the samples. Leaf-blade and petiole length and width were measured using a ruler and caliper, while apex, base, and venation angles were measured using a protractor (Baroga et al. 2004). Twenty-six (26) various characteristics of Cinnamomum cebuense were used in the analysis. Descriptions of the species based on their leaf architectural characteristics were compared to each other. The leaf architectural characteristics of Tabunan's C. cebuense described by Kosterman in 1986 served as the basis of comparison. Species whose leaf architectural characteristics were almost similar to Tabunan's Cinnamomum species were declared as similar species, while those species with majority of its leaf architectural characteristics different from Tabunan's Cinnamomum species were declared as another species.

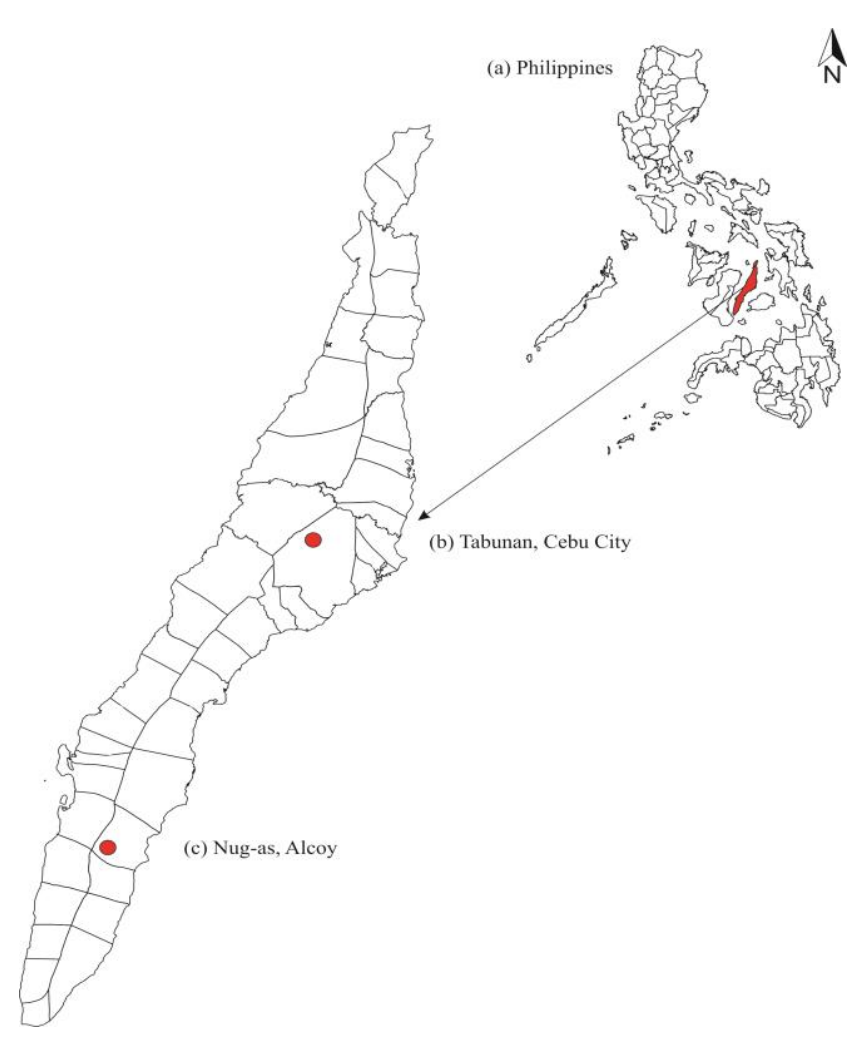

Figure 1. A. Study sites in Tabunan forest of Cebu City and Alcoy of Nug-as in Cebu Province, Philippines

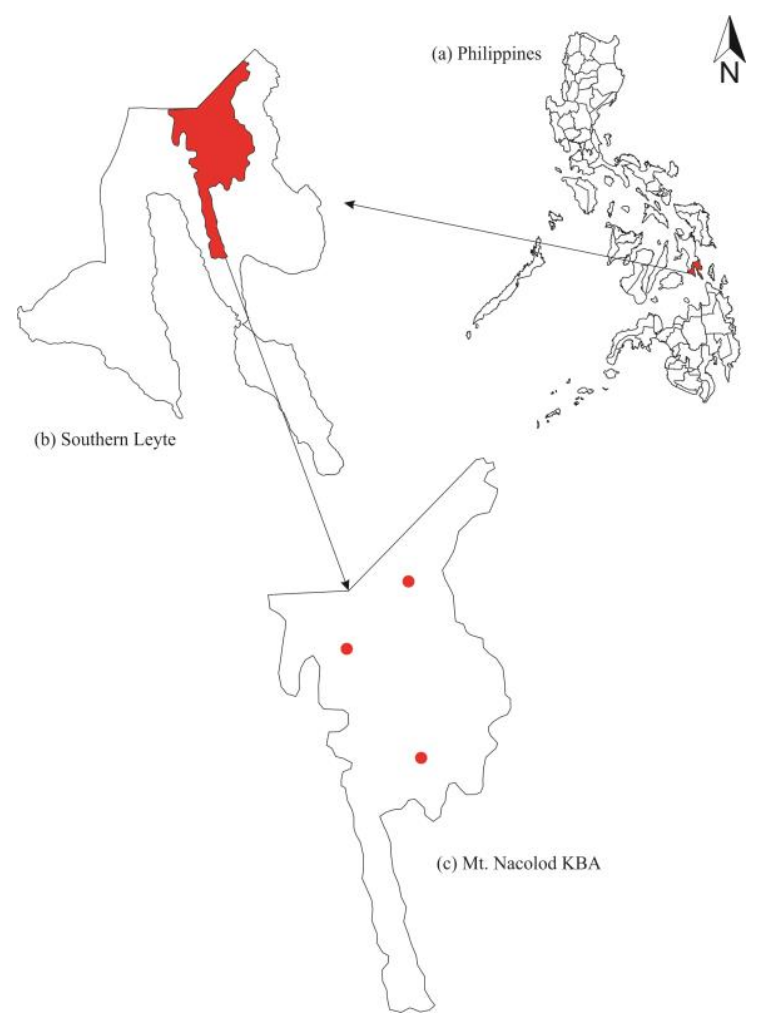

Figure 2. Study sites in Mount Nacolod in Southern Leyte Province, Philippines 


\section{RESULTS AND DISCUSSION}

\section{Description of Cinnamomum cebuense Kosterm}

Cinnamomum cebuense from Tabunan forest, Cebu City (Figure 3 ) has a mesophyll laminar size $(\mathrm{L}=187.91$ $\mathrm{mm}, \mathrm{W}=54.72 \mathrm{~mm}$ ) (e.g. Table 1). It has elliptic laminar shape and has symmetrical laminar symmetry. It has a laminar leaf length to width ratio of $4: 1$. Its base angle is obtuse and base shape is convex. Its apex angle and shape are acute and acuminate. Its $1^{0}$ and $2^{0}$ vein categories are acrodromous (basal), with simple agrophic veins. Its $2^{0}$ vein angle is one pair of acute basal secondaries. Its inter$2^{0}$ veins are weak intersecondaries, $3^{0}$ vein category is alternate percurrent, $3^{0}$ vein course is sinuous, $3^{0}$ vein angle to $1^{0}$ is obtuse, $3^{0}$ vein angle variability is inconsistent, $4^{0}$ vein category is alternate percurrent, and $5^{0}$ vein category is dichotomizing. It has an areolation of five or more sides and its marginal ultimate venation, looped without teeth.

The species from Nug-as, Alcoy, Cebu (Figure 4) has a notophyll laminar size $(\mathrm{L}=109.44 \mathrm{~mm}, \mathrm{~W}=40.28 \mathrm{~mm})$. Its laminar shapes are elliptic and ovate (e.g. Table 1). Its laminar leaf length to width ratio is $3: 1$, smaller compared to Tabunan's species. Its base angle is obtuse and base shape is convex, similar to Tabunan's Cinnamomum species. However, its apex shape is convex to acuminate, and its $1^{0}$ and $2^{0}$ vein categories are acrodromous (supra basal), with simple agrophic veins. Its $2^{0}$ vein spacing is also uniform. Its $2^{0}$ vein angle is one pair of acute basal secondaries. Its inter- $2^{0}$ veins are weak intersecondaries, $3^{0}$ vein category is alternate percurrent, $3^{0}$ vein course is sinuous, $3^{0}$ vein angle to $1^{0}$ is obtuse, $3^{0}$ vein angle variability is inconsistent, $4^{0}$ vein category is alternate percurrent, and $5^{0}$ vein category is dichotomizing. It has an areolation of five or more sides and its marginal ultimate venation, looped without teeth.

It can be noted that both populations are very similar in terms of leaf architectural characteristics. The Cinnamomum species collected from Nug-as, Alcoy and Tabunan forest can be considered as one species because majority of their leaf architectural characteristics and vein categories were the same (Table 1). Although the Nug-as, Alcoy population had a smaller leaf size and its $1^{\circ}$ and $2^{\circ}$ vein categories were classified as basal to suprabasal acrodromous, these differences in laminar size and shape of the C. cebuense in Nug-as, Alcoy and Tabunan forest were just minimal. It is safe to say that the Tabunan and Alcoy populations are one Cinnamomum cebuense species only. This is very clear as far as data in Table 1 is concerned.

On the other hand, the species from Mount Nacolod, Southern Leyte (Figure 5) has a microphyll laminar size, elliptic to ovate laminar shape, laminar length to width ratio of 3:1, base angle of acute to obtuse, base shape of acute to convex, apex angle of acute, and apex shape of acute to acuminate. Its $1^{0}$ and $2^{0}$ vein categories are acrodromous (supra basal), with simple agrophic veins, $2^{0}$ vein spacing is uniform, $2^{0}$ vein angle is one pair of acute basal secondaries, inter- $2^{0}$ veins are weak intersecondaries.
While its $3^{0}$ vein category mixed opposite/alternate, $3^{0}$ vein course is convex-sinuous, $3^{0}$ vein angle to $1^{0}$ is perpendicular-obtuse, $3^{0}$ vein angle variability is inconsistent. The $4^{0}$ vein category is alternate percurrent, and $5^{0}$ vein category is dichotomizing. It has an areolation of five or more sides and a marginal ultimate venation of looped without teeth (e.g. Table 1).

The species populations distributed in three geographical locations have more or less similar features from the primary to secondary venation characteristics. However, starting from the tertiary venation features, populations from Mount Nacolod in Southern Leyte were really having different characteristics. Many studies (Larano and Buot 2010, Tan and Buot 2019, Baltazar and Buot 2019a, Baltazar and Buot 2019b, among others) pointed out that in most cases, the tertiary venation characters really separate populations of different species. The findings implied that the cinnamon population of Mount Nacolod in Southern Leyte is a different species. This necessitates further investigation to really identify the Mount Nacolod species.

Leaf architecture is a very useful tool to recognize character differences among plants as it is genetically fixed (Roth-Nebelsick et al 2001). The study is in full agreement with the literature reviewed that leaf characters are useful in verifying similarities and dissimilarities, and hence, it can, therefore, be used to unify or discriminate one species from the other (e.g., Cinnamomum), especially, when flowers and fruits are unavailable. A study by Nurshahidah (2011) stated that the leaf venation can be used in the identification of species and has systematic significance for the genus Carallia. Banaticla and Buot 2004 had proven this too in their study of Psychotria species. Baltazar and Buot (2019) used leaf architecture in resolving the muchdebated issue between Coffea liberica and Coffea liberica var. dewevrei. Buot and his students at the Plant Systematics Laboratory of the University of the Philippines Los Banos, had been using leaf architecture as a tool in addressing taxonomic controversies among many Hoya species of the family Apocynaceae (Tan and Buot 2018, Baltazar and Buot 2019a, Jumawan and Buot 2016, Torrefiel and Buot 2017, Paguntalan and Buot 2019). In 2012, Celadina and colleagues, utilized leaf architecture to delineate various species of Cinnamomum in the Philippines. They were able to successfully characterize and identify each species using leaf architectural characters as well.

From the aforementioned discussion and based on Table 1, species populations in Nug-as, Alcoy, Cebu were Cinnamomum cebuense because majority of its leaf architectural characteristics and vein categories were similar to those of the populations in Tabunan forest, the type locality of Cinnamomum cebuense. However, the species from Mount Nacolod, Southern Leyte is a different Cinnamomum species because of the very different tertiary vein characters and other higher venation characters. 
Table 1. Leaf architectural characteristics delineating the Cinnamomum cebuense Kosterm (LAWG 1999)

\begin{tabular}{|c|c|c|c|}
\hline Characters & $\begin{array}{l}\text { Cinnamomum cebuense Koster } \\
\text { in Tabunan forest, Cebu } \\
\text { Exsicc. Lillo } 6528 \text { (PBDH) }\end{array}$ & $\begin{array}{l}\text { Cinnamomum cebuense Kosterm. } \\
\text { in Nug-as, Alcoy, Cebu } \\
\text { Exsicc. Lillo } 6530 \text { (PBDH) }\end{array}$ & $\begin{array}{l}\text { Cinnamomum sp. } \\
\text { in Mt. Nacolod, Southern Leyte } \\
\text { Exsicc. Lillo } 6527 \text { (PBDH) }\end{array}$ \\
\hline $\begin{array}{l}\text { Diagnostic features of } \\
\text { morphotype }\end{array}$ & $\begin{array}{l}\text { Large leaf, leaf apex is caudate, } \\
\text { thinner leaf and pronounced leaf } \\
\text { venation }\end{array}$ & $\begin{array}{l}\text { Smaller leaf compared to } \\
\text { Tabunan's species, the apex is not } \\
\text { caudate, thinner leaf and } \\
\text { pronounced leaf venation }\end{array}$ & $\begin{array}{l}\text { Smaller size leaf, thicker leaf, and } \\
\text { non-visible secondary veins }\end{array}$ \\
\hline Laminar size & $\begin{array}{l}\text { Mesophyll } \\
(\mathrm{L}=187.91 \mathrm{~mm} \\
\mathrm{W}=54.72 \mathrm{~mm})\end{array}$ & $\begin{array}{l}\text { Notophyll } \\
(\mathrm{L}=109.44 \mathrm{~mm} \\
\mathrm{W}=40.28 \mathrm{~mm})\end{array}$ & $\begin{array}{l}\text { Microphyll } \\
(\mathrm{L}=73.08 \mathrm{~mm}, \\
\mathrm{W}=22.62 \mathrm{~mm})\end{array}$ \\
\hline Laminar shape & Elliptic & Elliptic to ovate & Elliptic to ovate \\
\hline Laminar L: W Ratio & $4: 1$ & $3: 1$ & $3: 1$ \\
\hline Base angle & Obtuse & Obtuse & Acute to obtuse \\
\hline Base shape & Convex & Convex & Acute to convex \\
\hline Apex shape & Acuminate & Convex to acuminate & Acute to acuminate \\
\hline $1^{\circ}$ Vein category & Acrodromous (Basal) & $\begin{array}{l}\text { Acrodromous (Basal to Supra } \\
\text { basal) }\end{array}$ & Acrodromous (Supra basal) \\
\hline $2^{\circ}$ Vein category & Acrodromous (Basal) & $\begin{array}{l}\text { Acrodromous (Basal to Supra } \\
\text { basal) }\end{array}$ & Acrodromous (Supra basal) \\
\hline Agrophic veins & Simple agrophic & Simple agrophic & Simple-looped \\
\hline $3^{\circ}$ Vein category & alternate percurrent & alternate percurrent & Mixed opposite/ alternate \\
\hline $3^{\circ}$ Vein course & Sinuous & Sinuous & Convex-Sinuous \\
\hline $3^{\circ}$ Vein angle to $1^{\circ}$ & Obtuse & Obtuse & Perpendicular-obtuse \\
\hline
\end{tabular}

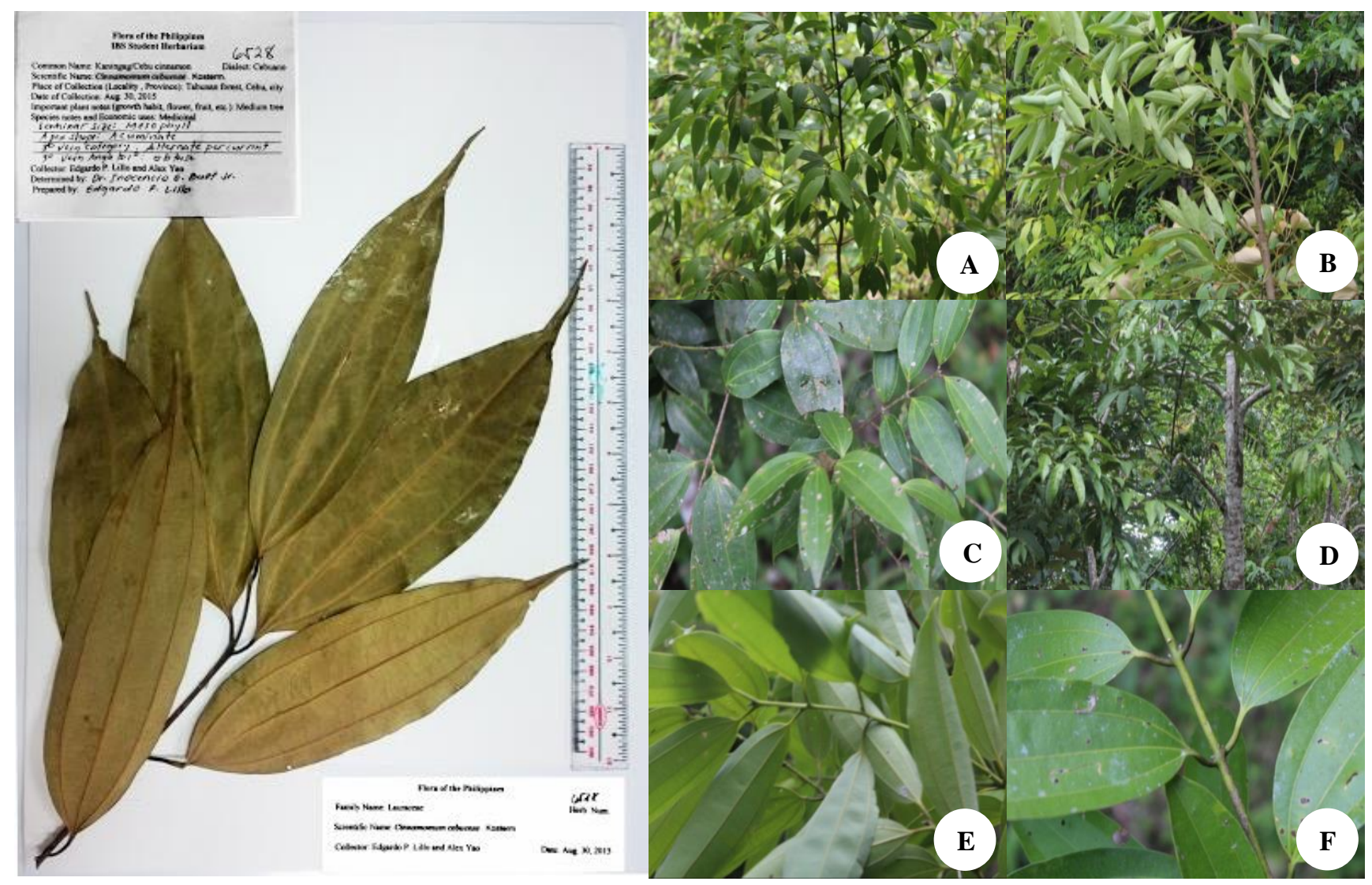

Figure 3. Cinnamomum cebuense Kosterm from Tabunan forest, Philippines (Herbarium and Fresh specimens). The fresh specimens showed the smplant habit and branches (A-D), the abaxial side of the leaf (E), and the adaxial side of the leaf (F). 

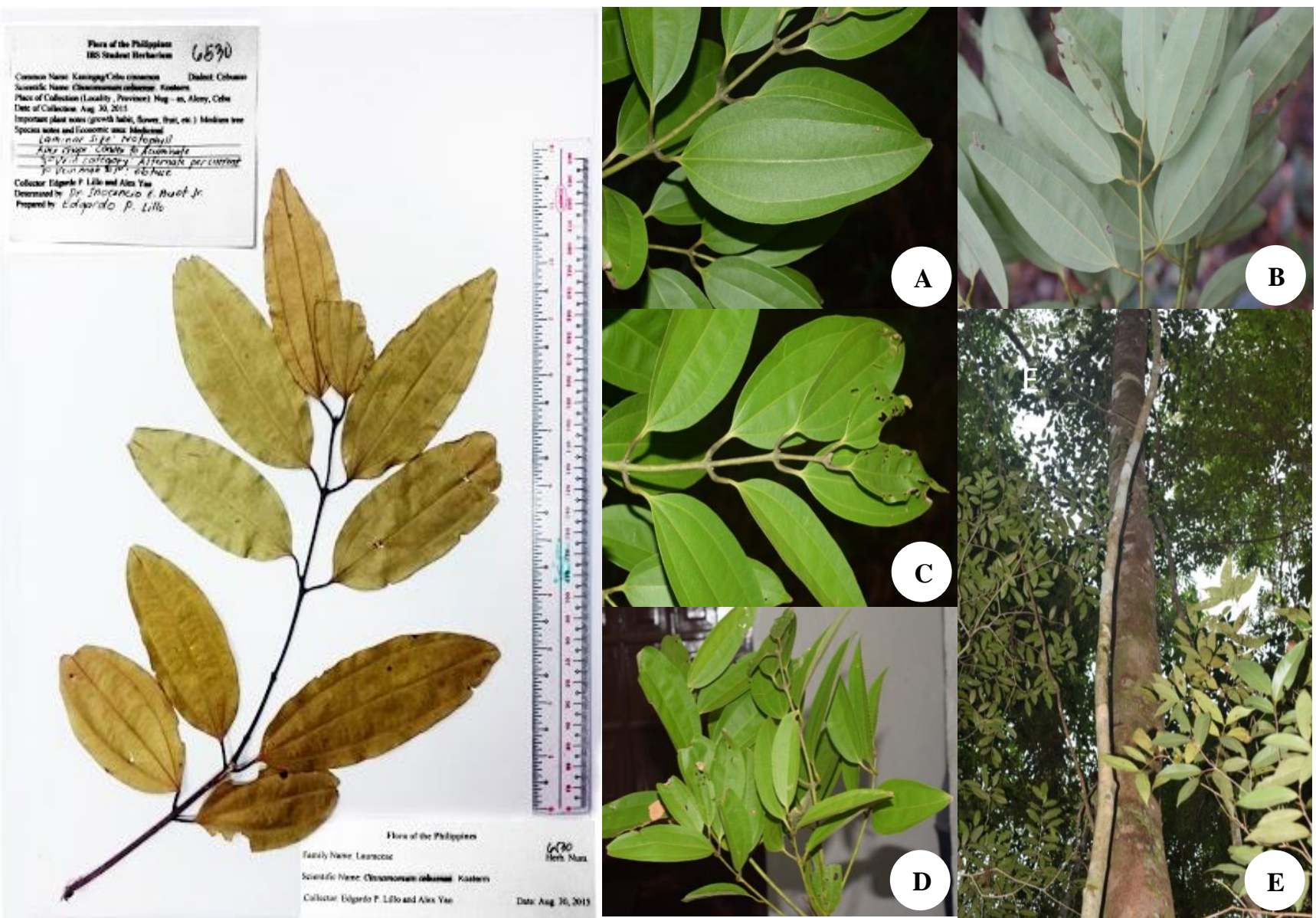

Figure 4. Cinnamomum cebuense Kosterm from Nug - as Alcoy, Cebu, Philippines (Herbarium and fresh specimens) exhibiting similar leaf architectural patterns as that of the $C$. cebuense in Tabunan forest. The fresh specimen showed a branch of the plant and the venation patterns (A-D) and the small plant (E)
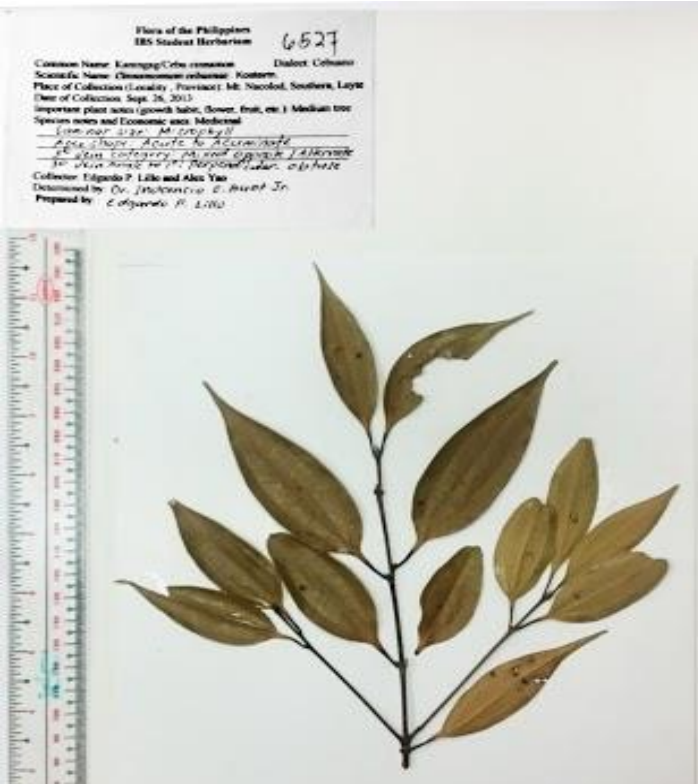

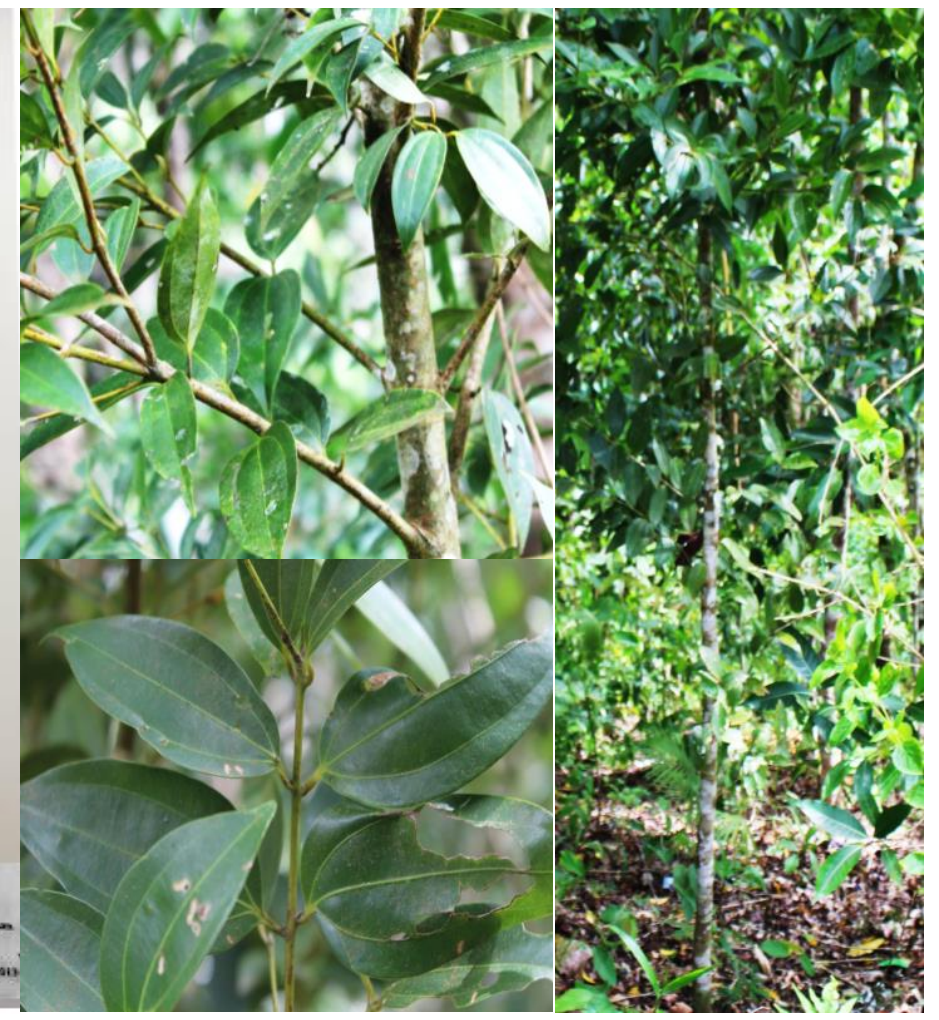

Figure 5. Cinnamomum cebuense Kosterm from Mount Nacolod of Southern Leyte, Philippines (Herbarium and Fresh specimens) 


\section{Conservation strategy of Cinnamomum cebuense Kosterm}

Loss of habitat of Cebu Island is the biggest threats to C. cebuense or Cebu cinnamon due to expanding urbanization and agricultural encroachment. The practice of bark stripping for medicinal use of the Cebu cinnamon also poses a threat to its survival as over-exploitation of this resource may lead to disease infection, or even death.

This Cebu endemic species need to be conserved and protected as populations are already endangered in the wild. The best strategy to conserve the species is to have a strong collaboration with the different stakeholders, LGU and local communities who are the leaders in the implementation of upscaled conservation initiatives particularly in relating to community-based forest and wildlife protection and conservation awareness. The move will strengthen the capacity of local community partners in implementing biodiversity conservation projects. Promoting the protection and conservation of $C$. cebuense in the area or forest where it could be found could result in a possible ecotourism destination.

\section{ACKNOWLEDGEMENTS}

The authors would like to acknowledge the Department of Science and Technology (DOST) for considering and approving our research proposal and giving us the budget for three years enough for the implementation of the whole study, and declaring CTU as one of the DOST-Biodiversity Centers through the NICER program in Region 7. The Philippine Council for Agriculture and Aquatic Resources Research Development (PCAARRD) endorsed our proposal to DOST for approval and guided us in the implementation of the study. The CTU System support to the research team was invaluable. The Forestry Department of the College of Technology and Engineering at CTU-Argao Campus was kind enough in allowing students to participate in the gathering of data. The DENR Region 7 gave the gratuitous permit. The CENRO Argao and Cebu City approved our request to conduct the study in different KBA. We would like also to acknowledge the keepers of the Plant Biodiversity Laboratory, Institute of Biological Sciences, College of Arts and Sciences and the Botany Laboratory, Department of Forest Biological Sciences, College of Forestry and Natural Resources, University of the Philippines Los Baños for allowing the researchers to use the facilities and conduct the study. The first author (EPL) thanks to his wife (Mary Jane) and son (CJ) for their moral support during the conduct of the study.

\section{REFERENCES}

Banaticla MCN, Buot IE Jr. 2004. Leaf architecture of ten Philippine Psychotria species (Rubiaceae). Philippine Sci 41: 74-90.

Baroga JB, Buot IE Jr. 2004. Leaf architecture of ten species of Philippine Terminalia Linn. (Combretaceae). Intl Res J Biol Sci 3 (3): 83-88.

Celadiña DA, Buot IE Jr, Madulid DA, Evangelista TT, Tandang D. 2012. Leaf architecture of selected Philippine Cinnamomum Schaeff. (Lauraceae) Species. Thail Nat Hist Mus J 6 (2): 89-111.

Fuller DQ, Hickey LJ. 2005. Systematics and leaf architecture of the Gunneraceae. Bot Rev 71 (3): 295-353.

Global Trees Campaign. 2011. Cebu Cinnamon. http://www.globaltrees.org/tp_cebu.htm.

Kpadehyea JT, Buot IE Jr. 2014. Leaf architecture of two species and nine infraspecific taxa of the Philippine Mussaenda Linn. (Rubiaceae): conservation concerns. Intl Res J Biol Sci 3 (10): 13-21.

Larano AAP, Buot IE Jr. 2010. Leaf architecture of selected species of Malvaceae sensu APG and its taxonomic significance. Philippine J Syst Biol 4: 211-254.

Leaf Architecture Working Group (LAWG). 1999. Manual of leaf architecture-Morphological description and categorization of dicotyledonous and net-veined monocotyledonous angiosperms. Smithsonian Institution, Washington, DC.

Loutfy MHA, Karakish EAK, Khalifa SF, Mira ERA. 2005. Numerical taxonomic evaluation of leaf architecture of some species of Genus Ficus L. Intl J Agric Biol 7 (3): 352-357.

Nurshahidah MR, Noraini T, Nurnida MK, Ruzi AR, Amalia NM, MohdArrabe' B. 2011. Systematic significance of leaf venation in Genus Carallia. Proceedings of the Universiti Malaysia Terengganu 10th International Annual Symposium (UMTAS) 2011, 11-13th July 2011. Permai Hotel, Kuala Terengganu, Malaysia.

Obico JJ, Bagay KC, Asencion AS, Medecillo MM. 2007. Comparative study of the leaf morphology of Epipremnum Schot and Rhaphidophora Hassk. (Araceae) in the Philippines. Philippine J Syst Biol 1 (1): 15-25.

Pi EX, Peng QF, Lu HF, Shen JB, Du YQ. 2009. Leaf morphology and anatomy of Camellia section Camellia (Theaceae). Bot J Linn Soc 159: 456-476. 